Jurnal Media Pertanian Vol. 2 No. 2 Tahun 2017 Hal. 65 - 72

Media Komunikasi Hasil Penelitian dan Review Literatur Bidang Ilmu Agronomi

ISSN print $2503-1279$ ISSN online $2581-1606$

\title{
PERTUMBUHAN STUMP OKULASI MATA TIDUR KARET (Hevea brasiliensis Muell Arg.) SETELAH MENGALAMI PENYIMPANAN PADA MEDIA SABUT KELAPA
}

\author{
Ridawati Marpaung \\ Program Studi Agroteknologi, Fakultas Pertanian Universitas Batanghari \\ Jl. Slamet Riyadi, Broni Jambi, 36122. Telp. +6274160103 \\ email : marpaungridawati@yahoo.com
}

\begin{abstract}
This study aimed to determine the growth eye stump of rubber after laying away in coconut fiber media. The design of this study was Completely Randomized Design with laying duration in coconut fiber medium $(P)$ as a treatment which consisting of 7 treatment levels e.g. P0: 0 day; P1:5 days; P2:10 days, P3:15 days; P4:20 days, P5: 25 days, and P6: 30 days storage. The result of this research showed that the growth of eye stump rubber after laying away on the coconut fiber medium was significantly influence the percentage of several parameters e.g. :starting of stump sprout, sprout height during storage, plant height, stem diameter, leaf number and leaf area total for each treatment except for the parameter percentage of eye stump rubber which not active yet. The freshness and the seedling viability of rubber plant originating from the eye stump rubber after laying away for 0-30 days in coconut fiber can be maintained. The highest growth was observed in the 20 to 30 days of laying away.
\end{abstract}

Keywords: stump sleeping eye grafting, storage, coconut husk

\begin{abstract}
Abstrak
Penelitian ini bertujuan untuk mengetahui pertumbuhan stum okulasi mata tidur Karet (Hevea brasiliensis Muell Arg.) setelah mengalami penyimpanan pada media sabut kelapa. Rancangan penelitian yang digunakan adalah Rancangan Acak Lengkap (RAL) dengan perlakuan percobaan lama penyimpanan stum okulasi mata tidur dalam media sabut kelapa $(\mathrm{P})$ yang terdiri dari 7 taraf perlakuan yaitu penyimpanan:P0: 0 hari; P1:5 hari ; P2:10 hari, P3: 15 hari ; P4: 20 hari, P5: 25 hari, dan P6: penyimpanan 30 hari. Hasil penelitian menunjukkan bahwa pertumbuhan stum okulasi mata tidur karet (Hevea brasiliensis Muell Arg.) setelah mengalami penyimpanan pada media sabut kelapa berpengaruh nyata terhadap peubah persentase stum okulasi mulai bertunas, tinggi tunas selama penyimpanan, tinggi tanaman, diameter batang, jumlah daun dan luas daun total untuk setiap perlakuan kecuali pada peubah persentase stum okulasi mata tidur yang belum aktif tumbuh. Kesegaran dan daya tumbuh bibit tanaman karet yang berasal dari stum mata tidur setelah disimpan selama 0-30 hari dalam media sabut kelapa dapat dipertahankan. Pertumbuhan tertinggi untuk setiap peubah yang diamati terdapat pada lama penyimpanan 20 hingga 30 hari.

Kata kunci : stump okulasi mata tidur, penyimpanan, sabut kelapa
\end{abstract}


Jurnal Media Pertanian Vol. 2 No. 2 Tahun 2017 Hal. 65 - 72

Media Komunikasi Hasil Penelitian dan Review Literatur Bidang Ilmu Agronomi

ISSN print $2503-1279$ ISSN online $2581-1606$

\section{PENDAHULUAN}

Tanaman karet (Hevea brasiliensis) adalah komoditi utama dalam bidang perkebunan yang merupakan produksi non migas dan menjadi sumber utama devisa negara yang cukup diperhitungkan. Karet dengan hasil utama getah (lateks) dugunakan sebagai bahan baku utama seperti peralatan transportasi, medis, dan alat-alat rumah tangga. Seiring dengan perkembangan teknologi dan industri serta tingginya kebutuhan lateks sebagai bahan baku industri sehingga mendorong dalam peningkatan produksi dari hasil tanaman tersebut.

Produksi karet (lateks) Indonesia masih berkisar 11,151 juta ton per tahunnya, dimana data ini menunjukkan bahwa hasil produksi lateks dari tanaman karet masih sangat rendah sehingga sangat perlu dilakukan perbaikan dan peningkatan hasil dari tanaman karet tersebut. Produktivitas perkebunan karet rakyat di Indonesia yang rendah ini disebabkan oleh kecendrungan petani karet menanam tanaman karet yang bukan berasal dari klon unggul. Kurangnya pengetahuan tentang klon unggul dan keterbatasan jumlah bahan klon unggul disetiap daerah pengembangan tanaman karet merupakan salah satu penyebab mengapa petani karet di Indonesia tidak menggunakan klon unggul. Upaya peningkatan hasil lateks untuk memenuhi kebutuhan akan lateks diperlukan teknologi yang tepat dalam pengelolaan bahan karet (Hero dan Purba, 2010).

Mengingat karet merupakan salah satu komoditas unggulan dan sebagai komoditi ekspor, maka budidaya tanaman karet harus terus dikembangkan dan direvitalisasi atau diremajakan dengan menggunakan klon-klon yang baik. Pemerintah telah menetapkan sasaran pengembangan produksi karet alam Indonesia sebesar 4 juta ton per tahun pada tahun 2025. Sasaran tersebut dapat tercapai bila pertanaman kebun karet rakyat yang sudah tua atau tidak produktif dilakukan peremajaan dengan menggunakan klon unggul yang bermutu. Pengembangan tanaman karet saat ini juga dilakukan dengan perluasan penanaman (ekstensifikasi). Melakukan perluasan lahan perkebunan karet tidak dapat diterapkan di sembarang daerah, karena setiap daerah memiliki karakteristik lahan yang berbeda, maka tidak semua tanaman dapat tumbuh di daerah tersebut. Dalam rangka ekstensifikasi pengembangan tanam karet, sumber daya iklim dan tanah harus diperhatikan. Salah satu syarat yang menentukan lokasi yang sesuai bagi tanaman karet adalah memperhatikan aspek agroklimatnya yaitu faktor iklim yang meliputi curah hujan, suhu, dan radiasi surya. Sedangkan faktor tanah yang perlu diperhatikan adalah sifat fisika, kimia dan topografi. Faktor-faktor inilah yang mempengaruhi pertumbuhan, perkembangan dan produksi tanaman karet.

Dalam rangka pengembangan budidaya tanaman karet dibutuhkan daerah-daerah yang memenuhi syarat secara agroklimat. Dearah-daerah tersebut adakalanya sangat jauh dari sumber-sumber bibit sebagai bahan tanaman. Untuk memenuhi kebutuhan bibit stum okulasi mata tidur tanaman karet ini tentu memerlukan pendistribusian melalui pengiriman dari sentra sentra yang menyediakan bibit menuju daerah pengembangan. Upaya dalam pengembangan budidaya tanaman karet di Indonesia secara menyeluruh tentunya perlu diperhatikan. Kendala yang sering dihadapi dalam pendistribusian bibit stump okulasi mata tidur adalah bagaimana cara untuk mempertahankan kesegaran dan daya tumbuh bibit selama pendistribusian dan penyimpanan menjelang penanaman pada lahan budidaya. Penggunaan media sabut kelapa selama penyimpanan dan pendistribusian stum okulasi mata tidur dapat mempertahankan kesegaran dan daya tumbuh bibit stum okulasi mata tidur tanaman karet. 
Jurnal Media Pertanian Vol. 2 No. 2 Tahun 2017 Hal. 65 - 72

Media Komunikasi Hasil Penelitian dan Review Literatur Bidang Ilmu Agronomi

ISSN print $2503-1279$ ISSN online $2581-1606$

Bahan tanaman karet yang dianjurkan adalah bahan klon yang diperbanyak secara okulasi. Penggunaan bahan klon secara okulasi dalam bentuk stum okulasi mata tidur sangat menguntungkan karena produktivitasnya tinggi, masa tanaman belum menghasilkan lebih pende, keseragaman tanaman lebih besar sehingga produksi tanaman pada tahun sadap pertama lebih tinggi, serta memiliki sifat sekunder yang diinginkan seperti relatif tahan terhadap penyakit tertentu, batang tegap, volume kayu per pohon tinggi (Http://ekosetianto.wordpress.com, 2009).

Stum sebagai bahan tanam ada kalanya didatangkan dari daerah lain atau keadaan lapang belum siap, sehingga stum harus disimpan dalam beberapa waktu. Inilah yang menjadi permasalahan dalam pemenuhan kebutuhan bibit tanaman karet, stump okulasi mata tidur untuk daerah pengembangan yang mempunyai jarak tempuh yang sangat jauh. Pemenuhan bibit tanaman karet ini melalui pengiriman menggunakan transportasi darat atau laut dari daerah asal bibit karet ke daerah tujuan pengembangan yang memerlukan waktu tempuh yang relatif lama. Suhu yang tinggi dan kelembaban udara yang relatif rendah selama pengangkutan dapat mengakibatkan proses fisiologi pada stum menjadi terganggu sehingga kondisi ini akan mengakibatkan stum menjadi rusak. Agar bibit stum okulasi mata tidur mutunya tetap baik sampai di lokasi penerimaan, maka penanganannya selama trasportasi dan penyimpanan harus dilakukan dengan baik. Salah satu cara yang dapat dilakukan untuk mempertahankan kesegaran dan daya hidup stum okulasi mata tidur selama transportasi dan penyimpanan (sebelum ditanam) adalah dengan melakukan pengemasan dalam media sabut kelapa dalam kondisi lembab (http:// petani top.blogspot.com/2016).

Sabut kelapa dapat dimanfaatkan sebagai media penyimpanan stum okulasi mata tidur karena kemampuan sabut kelapa untuk menyimpan air yang sangat baik. Sabut kelapa mampu menyerap dan menyimpan air enam kali lipat dari volumenya,dengan demikian akan dapa tmempertahankan kelembaban dan menjaga suhu lebih rendah dari kondisi normal atmosfir lingkungan. Selain itu sabut kelapa juga mengandung unsur hara berupa kalium $(\mathrm{K})$, phospor $(\mathrm{P})$, calsium $(\mathrm{Ca})$, magnesium $(\mathrm{MG})$, natrium $(\mathrm{Na})$ dan beberapa mineral lainnya (http://mitalom.com/2016).

Berdasarkan uraian di atas penulis telah melakukan penelitian tentang pertumbuhan stump okulasi mata tidur Karet (Hevea brasiliensis Muell Arg.) setelah mengalami penyimpanan pada media sabut kelapa".

\section{METODE PENELITIAN}

Penelitian ini telah dilakukan di kelurahan Pasir Putih, kecamatan Jambi Selatan, kota Jambi. Waktu penelitian dilakukan selama 3 bulan. Bahan-bahan yang digunakan dalam penelitian ini adalah stum okulasi mata tidur klon PB 260 yang berumur 1 tahun, sabut kelapa, polybag ukuran 30 x $40 \mathrm{~cm}$, pupuk kandang, pupuk urea, TSP dan $\mathrm{KCl}$, plastik hitam, atap rumbia, dan lain-lain yang dianggap perlu.Rancangan yang digunakan dalam penelitian ini adalah Rancangan Acak Lengkap (RAL), perlakuan yang dicobakan adalah lama penyimpanan stum okulasi mata tidur tanaman karet $(\mathrm{P})$ menggunakan media sabut kelapa yang terdiri dari 7 taraf perlakuan yaitu :P0:penyimpanan 0 hari; P1: penyimpanan selama 5 hari : $\mathrm{P} 2$ penyimpanan selama 10 hari ; P3: penyimpanan selama15 hari ; P4: penyimpanan selama20 hari ; P5: penyimpanan selama25 hari ; dan P6: penyimpanan selama30 hari ; Setiap perlakuan diulang 4 kali sehingga satuan percobaan berjumlah 28 , setiap satuan percobaan terdiri 
Jurnal Media Pertanian Vol. 2 No. 2 Tahun 2017 Hal. 65 - 72

Media Komunikasi Hasil Penelitian dan Review Literatur Bidang Ilmu Agronomi

ISSN print $2503-1279$ ISSN online $2581-1606$

dari 4 stum, 2 stum secara acak digunakan sebagai sample. Jumlah stum seluruhnya 112.

Peubah yang diamati sebelum bahan stum okulasi ditanam di polibag atau pada akhir penyimpanan adalah persentase stum okulasi yang belum aktif tumbuh, panjang tunas yang tumbuh selama penyimpanan, dan persentase stum okulasi mulai bertunas Sedangkan peubah yang diamati setelah bahan stum okulasi ditanam di polibag atau 10 minggu setelah tanam (MST) adalah tinggi tunas $(\mathrm{cm})$, diamater tunas $(\mathrm{mm})$, jumlah daun, dan luas daun total $\left(\mathrm{cm}^{2}\right)$.

Untuk melihat pengaruh lama penyimpanan stump okulasi mata tidur tanaman karet dalam media sabut kelapa terhadap peubah yang diamati, data dianalisis secara statistika menggunakan uji varian, kemudian dilanjutkan dengan uji jarak berganda Duncan (DNMRT) dengan taraf $\alpha 5 \%$.

\section{Hasil Pengamatan}

\section{HASIL DAN PEMBAHASAN}

\section{Persentase stum okulasi yang belum aktif tumbuh.}

Dari hasil analisis ragam diperoleh bahwa penyimpanan stum okulasi mata tidur tanaman karet dalam media sabut kelapa berpengaruh tidak nyata terhadap persentase stum okulasi yang belum aktif. Pengaruh masing masing perlakuan dapat dilihat pada Tabel 1.

Tabel 1. Rata-rata persentase stumokulasi yang belum aktif tumbuh pada hari terakhir penyimpanan

\begin{tabular}{cc}
\hline Lama penyimpanan (hari) & $\begin{array}{c}\text { Stum okulasiyang belum aktif } \\
\text { tumbuh }(\%)\end{array}$ \\
\hline $0(\mathrm{P} 0)$ & $100,00 \mathrm{a}$ \\
$5(\mathrm{P} 1)$ & $100,00 \mathrm{a}$ \\
$10(\mathrm{P} 2)$ & $100,00 \mathrm{a}$ \\
$15(\mathrm{P} 3)$ & $93,75 \mathrm{ab}$ \\
$20(\mathrm{P} 4)$ & $87,50 \mathrm{ab}$ \\
$25(\mathrm{P} 5)$ & $75,00 \mathrm{~b}$ \\
$30(\mathrm{P} 6)$ & $75,00 \mathrm{~b}$ \\
\hline
\end{tabular}

Ket. Angka-angka yang diikuti oleh huruf kecil yang sama berbeda tidak nyata menurut uji DNMRT taraf a $5 \%$

\section{Persentase stum okulasi mulai bertunas.}

Dari hasil analisis ragam diperoleh bahwa penyimpanan stum mata tidur tanaman karet dalam media sabut kelapa berpengaruh nyata terhadap persentase stum mulai bertunas. Pengaruh masing masing perlakuan dapat dilihat pada Tabel 2. 
Jurnal Media Pertanian Vol. 2 No. 2 Tahun 2017 Hal. 65 - 72

Media Komunikasi Hasil Penelitian dan Review Literatur Bidang Ilmu Agronomi ISSN print $2503-1279$ ISSN online $2581-1606$

Tabel 2. Rata-rata persentase stum okulasi mulai bertunas pada hari terakhir penyimpanan

\begin{tabular}{cc}
\hline Lama penyimpanan (hari) & Stum okulasi mulai bertunas (\%) \\
\hline $30(\mathrm{P} 6)$ & $59,93 \mathrm{a}$ \\
$25(\mathrm{P} 5)$ & $52,50 \mathrm{a}$ \\
$20(\mathrm{P} 4)$ & $48,75 \mathrm{a}$ \\
$15(\mathrm{P} 3)$ & $41,25 \mathrm{ab}$ \\
$10(\mathrm{P} 2)$ & $23,86 \mathrm{bc}$ \\
$5(\mathrm{P} 1)$ & $9,53 \mathrm{c}$ \\
0 (P0) & $2,71 \mathrm{c}$ \\
\hline
\end{tabular}

Ket. Angka-angka yang diikuti oleh huruf kecil yang sama berbeda tidak nyata menurut uji DNMRT taraf $\alpha 5 \%$

\section{Tinggi tunas stum okulasi mata tidur selama penyimpanan $(\mathrm{cm})$.}

Dari hasil analisis ragam diperoleh bahwa penyimpanan stum okulasi mata tidur tanaman karet dalam media sabut kelapa berpengaruh nyata terhadap tinggi tunas stum. Pengaruh masing masing perlakuan dapat dilihat pada Tabel 3.

Tabel 3. Rata-rata tinggi tunas stum okulasimata tidur selama penyimpanan

\begin{tabular}{cc}
\hline Lama penyimpanan (hari) & Rata-rata tinggi tunas stum okulasi mata tidur $(\mathrm{cm})$ \\
\hline $30(\mathrm{P} 6)$ & $3,23 \mathrm{a}$ \\
$25(\mathrm{P} 5)$ & $1,72 \mathrm{~b}$ \\
$20(\mathrm{P} 4)$ & $1,65 \mathrm{~b}$ \\
$15(\mathrm{P} 3)$ & $1,49 \mathrm{bc}$ \\
$10(\mathrm{P} 2)$ & $1,48 \mathrm{bc}$ \\
$5(\mathrm{P} 1)$ & $1,30 \mathrm{bc}$ \\
$0(\mathrm{P} 0)$ & $1,03 \mathrm{c}$ \\
\hline
\end{tabular}

Ket. Angka-angka yang diikuti oleh huruf kecil yang sama berbeda tidak nyata menurut uji DNMRT taraf $\alpha 5 \%$

\section{Tinggi bibit tanaman karet $(\mathbf{c m})$.}

Dari hasil analisis ragam diperoleh bahwa penyimpanan stum okulasi mata tidur tanaman karet dalam media sabut kelapa berpengaruh nyata terhadap tinggi bibit tanaman karet (10 MST). Pengaruh masing masing perlakuan dapat dilihat pada Tabel 4 .

Tabel 4. Rata-rata tinggi bibit tanaman karet di pembibitan (10 MST)

\begin{tabular}{cc}
\hline Lama penyimpanan (hari) & Tinggi bibit tanaman karet $(\mathrm{cm})$ \\
\hline 30 (P6) & $36,23 \mathrm{a}$ \\
25 (P5) & $35,85 \mathrm{a}$ \\
20 (P4) & $33,98 \mathrm{a}$ \\
15 (P3) & $33,68 \mathrm{a}$ \\
10 (P2) & $33,40 \mathrm{a}$ \\
5 (P1) & $27,27 \mathrm{~b}$ \\
0 (P0) & $27,21 \mathrm{~b}$ \\
\hline
\end{tabular}

Ket. Angka-angka yang diikuti oleh huruf kecil yang sama berbeda tidak nyata menurut uji DNMRT taraf $\alpha 5 \%$ 
Jurnal Media Pertanian Vol. 2 No. 2 Tahun 2017 Hal. 65 - 72

Media Komunikasi Hasil Penelitian dan Review Literatur Bidang Ilmu Agronomi

ISSN print $2503-1279$ ISSN online $2581-1606$

\section{Diameter batang bibit tanaman karet (mm).}

Dari hasil analisis ragam diperoleh bahwa penyimpanan stumokulasi mata tidur tanaman karet dalam media sabut kelapa berpengaruh nyata terhadap diameter bibit tanaman karet. Pengaruh masing masing perlakuan dapat dilihat pada Tabel 5.

Tabel 5. Rata-rata diameter batang bibit tanaman karet (10 MST)

\begin{tabular}{cc}
\hline Lama penyimpanan (hari) & Diameter batang bibit tanaman karet (mm) \\
\hline 30 (P6) & $8,04 \mathrm{a}$ \\
25 (P5) & $7,99 \mathrm{a}$ \\
20 (P4) & $7,59 \mathrm{ab}$ \\
15 (P3) & $7,40 \mathrm{ab}$ \\
10 (P2) & $7,14 \mathrm{bc}$ \\
5 (P1) & $6,98 \mathrm{bc}$ \\
0 (P0) & $6,49 \mathrm{c}$ \\
\hline
\end{tabular}

Ket. Angka-angka yang diikuti oleh huruf kecil yang sama berbeda tidak nyata menurut uji DNMRT taraf $\alpha 5 \%$

\section{Luas total daun bibit tanaman karet $\left(\mathrm{cm}^{2}\right)$.}

Dari hasil analisis ragam diperoleh bahwa penyimpanan stum okulasi mata tidur tanaman karet dalam media sabut kelapa berpengaruh nyata terhadap luas daun bibit tanaman karet. Pengaruh masing masing perlakuan dapat dilihat pada Tabel 6.

Tabel 6. Rata-rata luas total daun bibit tanaman karet (10 MST).

\begin{tabular}{cc}
\hline Lama penyimpanan (hari) & Rata-rata total luas daun bibit tanaman karet $\left(\mathrm{cm}^{2}\right)$ \\
\hline $30(\mathrm{P} 6)$ & $1,313 \mathrm{a}$ \\
$25(\mathrm{P} 5)$ & $1,302 \mathrm{a}$ \\
$20(\mathrm{P} 4)$ & $1,291 \mathrm{a}$ \\
$15(\mathrm{P} 3)$ & $1,282 \mathrm{a}$ \\
$10(\mathrm{P} 2)$ & $1,204 \mathrm{ab}$ \\
$5(\mathrm{P} 1)$ & $1,014 \mathrm{~b}$ \\
0 (P0) & $1,005 \mathrm{~b}$ \\
\hline
\end{tabular}

Ket. Angka-angka yang diikuti oleh huruf kecil yang sama berbeda tidak nyata menurut uji DNMRT taraf $\alpha 5 \%$

\section{Pembahasan}

Dari hasil percobaan dan hasil analisis ragam menunjukkan bahwa daya tumbuh stum okulasi mata tidur tanaman karet setelah penyimpanan hingga 30 hari dalam media sabut kelapa dapat dipertahankan dan pertumbuhan stump okulasi mata tidur di polibag selama percobaan dalam keadaan baik dan normal. Setiap perlakuan memberikan pengaruh berbeda nyata untuk semua peubah yang diamati, kecuali peubah stum okulasi yang belum aktif

Dari peubah-peubah yang diamati, menunjukkan persentase stum yang belum aktif tumbuh hingga penyimpanan 30 hari dalam kemasan sabut kelapa 75 hingga 100 $\%$. Persentase tertinggi stum mulai bertunas pada akhir penyimpanan diperoleh pada penyimpanan 20 hingga 30 hari. Daya tumbuh stum okulasi dapat dipertahankan dalam kemasan sabut kelapa. Pertumbuhan stum okulasi mata tidur tanaman karet tetap terjadi dalam media sabut kelapa selama penyimpanan dengan menggunakan cadangan 
Jurnal Media Pertanian Vol. 2 No. 2 Tahun 2017 Hal. 65 - 72

Media Komunikasi Hasil Penelitian dan Review Literatur Bidang Ilmu Agronomi

ISSN print $2503-1279$ ISSN online $2581-1606$

makanan yang terdapat pada stum okulasi. Semakin lama penyimpanan, tunas yang tumbuh juga semakin panjang. Upaya untuk mempertahankan daya tumbuh bibit stum okulasi selama penyimpanan dapat dilakukan dengan memperhatikan faktor-faktor yang dapat mempengaruhinya yaitu suhu, kelembaban, kadar air dan wadah simpan. Media sabut kelapa yang lembab yang digunakan dalam penyimpanan stum okulasi mata tidur ini,dapat menciptakan dan mempertahankan kondisi kelembaban yang tinggi dan suhu yang rendah.

Daya tumbuh stum okulasi mata tidur dapat dipertahankan dalam kemasan sabut kelapa karena sabut kelapa dapat menampung air hingga enam kali lebih banyak dari volume yang dimilikinya sehingga dapat mempertahankan kelembaban stum okulasi yang dikemas. Selain itu media sabut kelapa yang lembab mempunyai suhu rendah. Pada suhu penyimpanan yang rendah mengakibatkan laju respirasi dan laju transpirasi stum okulasi dapat ditekan sehingga periode penyimpanan stum okulasi dapat diperpanjang tanpa menimbulkan kematian. Selain kemampuan menjaga kelembaban dan suhu, sabut kelapa juga mengandung unsur hara makro seperti $\mathrm{K}, \mathrm{P}, \mathrm{Ca}, \mathrm{Mg}, \mathrm{N}$ dan beberapa mineral seperti $\mathrm{Fe}, \mathrm{Mn}, \mathrm{B}, \mathrm{Mo}, \mathrm{Cu}, \mathrm{Zn}, \mathrm{Co}, \mathrm{Si}$ dan Ni (http://prosespembuatan-pupuk-organik-cair-dari-sabut-kelapa, 2016). Kandungan nutrisi dalam sabut kelapa ini tentunya akan turut mendukung daya awet dan daya tumbuh stum selama penyimpanan.

Dari peubah-peubah yang diamati pada stum okulasi mata tidur, setelah ditanam di polibag seperti tinggi tanaman, diameter batang, jumlah daun dan luas total daun, menunjukkan perbedaan yang nyata untuk setiap perlakuan. Pertumbuhan bibit tanaman karet selama pengamatan di polibag berlangsung dengan baik. Pertumbuhan bibit berlangsung secara normal, dan pertumbuhan tertinggi pada keempat peubah yang diamati terdapat pada penyimpanan 15 hingga 30 hari. Pertumbuhan stum okulasi mata tidur ini merupakan kelanjutan dari pertumbuhan stum okulasi yang telah terjadi selama penyimpanan. Setelah stum okulasi ditanam di polibag pertumbuhan berlanjut secara normal.

\section{KESIMPULAN}

Dari hasil penelitian dan hasil analisis ragam dapat disimpulkan sebagai berikut:

1. Penyimpanan pada media sabut kelapa berpengaruh nyata terhadap peubah persentase stum okulasi mulai bertunas, tinggi tunas selama penyimpanan, tinggi tanaman, diameter batang, jumlah daun dan luas daun total untuk setiap perlakuan kecuali pada peubah persentase stum okulasi mata tidur yang belum aktif tumbuh.

2. Pertumbuhan tertinggi untuk setiap peubah yang diamati terdapat pada lama penyimpanan 20 hingga 30 hari.

\section{DAFTAR PUSTAKA}

Http://cybex.pertanian.go.id/materi penyuluhan /detail/8936/pembibitan-karetdengan-okulasi. Diakses tanggal 30 Januari 2017.

Http://mitalom.com/beragam-manfaat-sabut-kelapa. Diakses tanggal 30 Januari 2017

Http://ekosetianto.wordpress.com/2009/11/07/teknisi-budidaya-tanaman-karet. Diakses tanggal 30 januari 2017.

Http://petanitop.blogspot.com/2016/01/ca-pengemasan-stum-okulasi-mata-tidur.html. Diakses tanggal 30 Januari 2017 
Jurnal Media Pertanian Vol. 2 No. 2 Tahun 2017 Hal. 65 - 72

Media Komunikasi Hasil Penelitian dan Review Literatur Bidang Ilmu Agronomi

ISSN print $2503-1279$ ISSN online $2581-1606$

http://text-id.123dok.com/document/wq2nj1rq-pertumbuhan-stum-mata-tidur-karethevea-brasiliensis-muell-arg-dengan-pemberian-air-kelapa-dan-lamapenyimpanan-pada-kertas-koran.html Diakses Tanggal 29 Januari 2017.

http://mesin pengolah sabut kelapa.wordpress.com/2016/08/17/proses-pembuatanpupuk-organik-cair-dari-sabut-kelapa, 2016). Diakses tanggal 3 Juni 2017

Oetomo Soewito, S. 1981. Percobaan Penyimpanan dan Pengiriman Bibit Karet Jarak Jauh Dalam Waktu Lama. Pertemuan teknis Perkebunan II di Surakarta.

Sentiono dan Seosolo, 1986. Mengirim Bibit Karet Stump Mata Tidur Jarak Jauh dan Cara Pengelolaanya Di Lokasi Penerima. Kumpulan Pertemuan Teknis Perkebunan Karet dan R.C Getas.

Tim Penulis, 2008. Panduan Lengkap Karet. Penebar Swadaya, Anggota IKAPI. 